\title{
A New Route to Carbonate Monomers for Synthesis of Polycarbonates
}

\author{
Gabriel RoKICKI, Jerzy PAWLICKI, and Witold KURAN \\ Institute of Organic Chemistry and Technology, Technical University, \\ Politechnika, Koszykowa 75, 00-662 Warsaw, Poland
}

(Received March 31, 1982)

\begin{abstract}
A number of carbonates $\left(\mathrm{RCH}_{2}\right)_{2} \mathrm{CO}_{3}\left(\mathrm{R}=\mathrm{CH}_{3}, \mathrm{C}_{2} \mathrm{H}_{5}, \mathrm{CH}_{2}=\mathrm{CH}, \mathrm{C}_{3} \mathrm{H}_{7}\right.$, $\mathrm{C}_{5} \mathrm{H}_{11}, \mathrm{C}_{6} \mathrm{H}_{5}$ ) have been synthesized by the reaction of alkali metal carbonates with corresponding halogen derivatives in the presence of activating agents such as crown ethers, polyglymes, polyamines, and triethylbenzylammonium chloride. The effects of various parameters (type of the halogen derivative, metal carbonate, activating agent, solvent and reaction time) on the reaction yield have been studied. The carbonates obtained were used as monomers in transesterification with diols and diphenols leading to the formation of polycarbonates. The polycarbonates obtained were characterized by means of IR spectroscopy and their intrinsic viscosity was determined.
\end{abstract}

KEY WORDS Alkali Metal Carbonate / Crown Ether / Polyglyme / Dialkyl Carbonate / Transesterification / Polycarbonate /

Polycarbonates, being alkyl or aryl esters of carbonic acid, can be obtained by direct or indirect application of phosgenation processes. For example, the most commonly known polycarbonate, poly $\left(4,4^{\prime}\right.$-isopropylidenediphenylene carbonate), is obtained from the reaction of phosgene with disodium salt of 2,2-bis(4-hydroxyphenyl)propane or from transesterification of diphenyl carbonate with 2,2-bis(4-hydroxyphenyl)propane.

Lately, a number of papers have appeared on the preparation of polycarbonates via condensation by the direct use of $\mathrm{CO}_{2}$, dipotassium salts of cyclohexanediol or 2,2-bis(4-hydroxyphenyl)propane and $p$-xylylene $\alpha, \omega$-dibromide ${ }^{1,2}$ and from the reaction of potassium carbonate with aliphatic $\alpha, \omega$-dibromides. ${ }^{3}$ The molecular weight of the polycarbonates obtained by this method reached as much as 30,000 but the polymer yield did not exceed $50 \%$.

In this paper a new two-step method for the preparation of polycarbonates using alkali metal carbonates without phosgene as a reagent is proposed. In the first step, the monomers dialkyl carbonates are obtained (eq 1). In this step the alkyl halide reacts with the alkali metal carbonate in the presence of an agent which complexes the metal cation, thus activating the carbonate anions. In the next step, the carbonate monomers undergo transesterification with diols or diphenols to form the corresponding carbonates (eq 2).
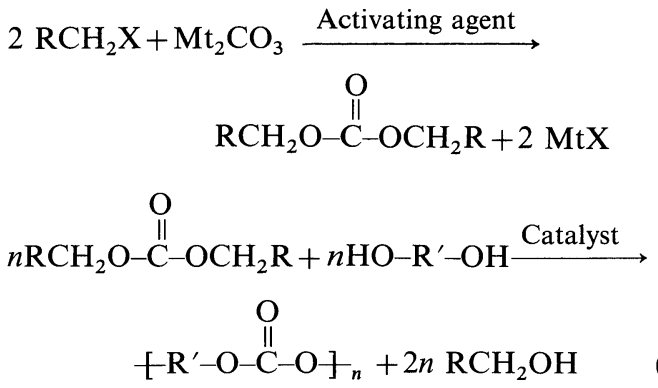

$$
\mathrm{Mt}=\mathrm{K}, \mathrm{Na}
$$$$
\mathrm{R}=\mathrm{C}_{6} \mathrm{H}_{5}, \quad \mathrm{CH}_{2}=\mathrm{CH}, \quad \mathrm{CH}_{3}, \mathrm{C}_{2} \mathrm{H}_{5}, \quad \mathrm{C}_{3} \mathrm{H}_{7},
$$
$\mathrm{C}_{5} \mathrm{H}_{11}$

$$
\begin{aligned}
& \mathrm{X}=\mathrm{Br}, \mathrm{Cl} \\
& \mathrm{R}^{\prime}=\text { alkylene, arylene }
\end{aligned}
$$

In the proposed method, the alcohol and alkali metal halide can be recycled to obtain the alkyl halide.

Monomers of the dialkyl carbonate type are obtained classically using phosgene and by the reaction of silver carbonate with alkyl iodides. Recently Sakai et $a .^{4}$ described the method of 
preparation of dialkyl carbonates by the reaction of $\mathrm{CO}_{2}$ with dialkoxydibutyltin. This method was next developed by Yamazaki et al. ${ }^{5}$ who showed the possibility of the preparation of carbonates from $\mathrm{CO}_{2}$ and alcohols in the presence of dialkoxydibutyltin.

This paper describes the results of reactions of alkali metal carbonates with alkyl halides in the presence of activating agents (eq 1) and attempts to synthesize polycarbonates (eq 2) using the carbonate monomers obtained according to eq 1 .

\section{EXPERIMENTAL}

\section{Materials}

Benzyl bromide was obtained by bromination of toluene under UV-irradiation and purified by distillation. Benzyl chloride, aliphatic bromo-derivatives and allyl chloride and bromide were commercial grade and purified according to known methods. Butylene glycol, $p$-xylylene glycol, and bisphenol A (2,2-bis(4-hydroxyphenyl)propane), were commercial grade and used without further purification. The metal carbonates were used after exact powdering and drying under reduced pressure at $120^{\circ} \mathrm{C}$. Ethylpotassium carbonate was obtained by passing $\mathrm{CO}_{2}$ through an alcoholic solution of potassium ethanolate. Crown ethers, 18-crown-6 (1,4,7,10, 13,16-hexaoxacyclooctadecane) and DB-18-crown6 (dibenzo-1,4,7,10,13,16-hexaoxacyclooctadecane) were obtained according to the method of Gokel and Cram. ${ }^{6}$ Polyglyme 600 was obtained from the reaction of the polyethylene glycol 600 disodium salt with methyl bromide. Polyamines, TMEDA $\left(N, N, N^{\prime}, N^{\prime}\right.$-tetramethylethylenediamine) and DABCO (1,4-diazabicyclo[2.2.2]octane) were commercial products from FLUKA AG. TEBA (triethylbenzylammonium chloride) was obtained by a known method using triethylamine and benzyl chloride. The solvents used for the reaction were purified by known methods.

\section{Synthesis and Characterization of Dialkyl Car- bonates}

In a $50 \mathrm{~cm}^{3}$ glass reaction vessel, required amounts of metal carbonate, halogen derivative, metal cation complexing agent and finally a solvent were placed. The reaction vessel was then heated at the required temperature for $48 \mathrm{~h}$, or for a shorter time while continuosly stirring the contens. After completion of the reaction, the metal halide formed and/or the unreacted metal carbonate were filtered off and the filtrate was washed with water to extract the metal cation complexing agent and remaining salt. The excess halogen derivative was then distilled off from the filtrate.

IR analysis of the carbonate monomers obtained (Perkin-Elmer 521 spectrometer) showed the presence of strong characteristic absorption bands in the range $1750 \mathrm{~cm}^{-1}$ and $1230-1280 \mathrm{~cm}^{-1}$ corresponding to the stretching vibrations of carbonyl and oxycarbonyl linear carbonate bonds, respectively. Also ${ }^{1} \mathrm{H}$ NMR studies $(100 \mathrm{MHz}$ JEOL, NMR spectrometer, TMS as internal standard) of the carbonates obtained confirmed their structure; e.g., for dibenzyl carbonate $\delta_{\mathrm{CH}_{2}}=5.2 \mathrm{ppm}(\mathrm{s})$ $\delta_{\mathrm{CH} \text { arom. }}=7.5 \mathrm{ppm}(\mathrm{s})(4: 10)$.

The yields of the dialkyl carbonates obtained were determined by gas chromatography (Chrom-4 apparatus, Czechoslovakia, SE-30 column; carrier, hydrogen, vaporizer temperature, $160^{\circ} \mathrm{C}$; temperature of column, $120^{\circ} \mathrm{C}$ ). The yields of dibenzyl carbonate and diallyl carbonate were determined on the basis of ${ }^{1} \mathrm{H}$ NMR spectra of postreaction mixtures containing the carbonate and unreacted substances, by comparing the intensity of the signals and corresponding protons in the carbonate and halide. The yield of dibenzyl carbonate was also determined by liquid chromatograph (Zorbax TMSil column; eluent, $13 \% \mathrm{CHCl}_{3}$ in hexane, room temperature). The dibenzyl carbonate standard was obtained from transesterification of diethyl carbonate with benzyl alcohol.

\section{Transesterification and Product Characterization}

In a $50 \mathrm{~cm}^{3}$ glass reaction vessel, required equimolar amounts of dialkyl carbonate, diol or bisphenol A, and a catalyst $(2 \mathrm{wt} \%$ ) were placed under nitrogen. The reaction vessel was then heated in a thermostated oil bath. After completion of the reaction the side products and, in the case of bisphenol $\mathrm{A}$, the excess diethyl carbonate were distilled off.

The carbonates obtained were analyzed by IR spectroscopy (Perkin-Elmer 521 spectrometer) and their intrinsic viscosity was determined using an Ubbelohde viscometer at $25^{\circ} \mathrm{C}$ in $\mathrm{CHCl}_{3}$ as the solvent. 


\section{RESULTS AND DISCUSSION}

The reactions (eq 1) of different organic halides with several metal carbonates using various metal cation complexing agents as carbonate anion activators in nucleophilic substitution were carried out. The effect of the halogen derivative used in excess in the reaction with $\mathrm{K}_{2} \mathrm{CO}_{3}$ in the presence of 18crown- 6 on the dialkyl carbonate was examined and the yield is presented in Table I. Benzyl bromide and allyl bromide appeared to be the most reactive halides, and the yields of the corresponding carbonates reached nearly $100 \%$ with respect to the $\mathrm{K}_{2} \mathrm{CO}_{3}$ used. In the case of $t$-butyl bromide, no corresponding carbonate was obtained; an elimination reaction takes place here and isobutylene is formed.

The yield of the reaction expressed by eq 1 was found to depend to a great extent on the type of the activating agent of the carbonate anion. In Table II, the effect of the type of a complexing agent on the yield of dibenzyl carbonate is presented. The greatest yields were obtained when using 18-crown-6 and DB-18-crown-6. A high yield of dibenzyl carbonate, reaching $75 \%$ based on $\mathrm{K}_{2} \mathrm{CO}_{3}$, was also obtained when using polyglyme of a molecular weight of 600 instead of the crown ethers. Polyamines, DABCO and TMEDA, usually used in

Table I. Yield of carbonate monomers from the reaction of $\mathrm{K}_{2} \mathrm{CO}_{3}$ with different halogen derivatives $\mathrm{RCH}_{2} \mathrm{X}^{\mathrm{a}}$

\begin{tabular}{|c|c|c|c|c|c|c|c|c|}
\hline & \multirow{2}{*}{\multicolumn{2}{|c|}{$\mathrm{RCH}_{2} \mathrm{X}$}} & \multirow{2}{*}{\multicolumn{2}{|c|}{$\mathrm{K}_{2} \mathrm{CO}_{3}$}} & \multirow{3}{*}{$\frac{\text { Temp }}{{ }^{\circ} \mathrm{C}}$} & \multicolumn{3}{|c|}{ Carbonate monomer } \\
\hline & & & & & & hn (lit) & hn (Found) & Yield \\
\hline & g & mmol & g & $\mathrm{mmol}$ & & ${ }^{\circ} \mathrm{C}$ & ${ }^{\circ} \mathrm{C}$ & $\%$ \\
\hline Benzyl bromide & 14.4 & 84.2 & 0.6 & 4.3 & 80 & $200-201(13.5 \mathrm{~mm})^{8}$ & $185-190(2 \mathrm{~mm})$ & $98^{\mathrm{b}}$ \\
\hline Benzyl chloride & 11.0 & 87.0 & 0.6 & 4.3 & 80 & & & 51 \\
\hline Ethyl bromide & 14.5 & 133.0 & 0.6 & 4.3 & 42 & $125.8^{9}$ & $124-125$ & 35 \\
\hline$n$-Propyl bromide & 13.5 & 109.8 & 0.6 & 4.3 & 70 & $67.5-67.8(17 \mathrm{~mm})^{9}$ & $168-169$ & 25 \\
\hline$n$-Butyl bromide & 13.0 & 94.9 & 0.6 & 4.3 & 80 & 96-98 $(17 \mathrm{~mm})^{9}$ & $90-92(15 \mathrm{~mm})$ & 33 \\
\hline$t$-Butyl bromide & 13.0 & 94.9 & 0.6 & 4.3 & 70 & & & 0 \\
\hline$n$-Hexyl bromide & 6.0 & 36.3 & 1.2 & 8.6 & 80 & $152-154(20 \mathrm{~mm})^{9}$ & $150-153(16 \mathrm{~mm})$ & 12 \\
\hline Allyl bromide & 13.9 & 114.9 & 0.6 & 4.3 & 70 & $72-75(30 \mathrm{~mm})^{10}$ & $60-63(13 \mathrm{~mm})$ & $95^{\mathrm{b}}$ \\
\hline Allyl chloride & 14.1 & 185.0 & 0.6 & 4.3 & 45 & & & 2 \\
\hline
\end{tabular}

a 18 -Crown-6 ether, $0.1 \mathrm{~g}(0.38 \mathrm{mmol})$; time, $48 \mathrm{~h}$.

b After $24 \mathrm{~h}$.

Table II. Effect of carbonate anion activating agents on the yield of the reaction of $\mathrm{K}_{2} \mathrm{CO}_{3}$ with benzyl bromide and benzyl chloride ${ }^{\mathrm{a}}$

\begin{tabular}{|c|c|c|c|c|}
\hline \multirow{3}{*}{ Activating agent } & \multirow{3}{*}{$\mathrm{g}$} & \multirow{3}{*}{$\mathrm{mmol}$} & \multicolumn{2}{|c|}{ Yield of carbonate from } \\
\hline & & & Benzyl bromide & Benzyl chloride \\
\hline & & & $\%$ & $\%$ \\
\hline 18-Crown-6 & 0.1 & 0.38 & 98 & 51 \\
\hline DB-18-Crown-6 & 0.1 & 0.27 & 87 & 32 \\
\hline TEBA & 0.087 & 0.38 & 45 & 10 \\
\hline DABCO & 0.043 & 0.38 & 32 & 15 \\
\hline TMEDA & 0.1 & 0.87 & 50 & 33 \\
\hline Polyglyme 600 & 0.5 & 0.83 & 75 & 12 \\
\hline
\end{tabular}

${ }^{a}$ Benzyl halide, $84.2 \mathrm{mmol} ; \mathrm{K}_{2} \mathrm{CO}_{3}, 0.6 \mathrm{~g}(4.34 \mathrm{mmol})$; temp, $80^{\circ} \mathrm{C}$; time, $48 \mathrm{~h}$. 


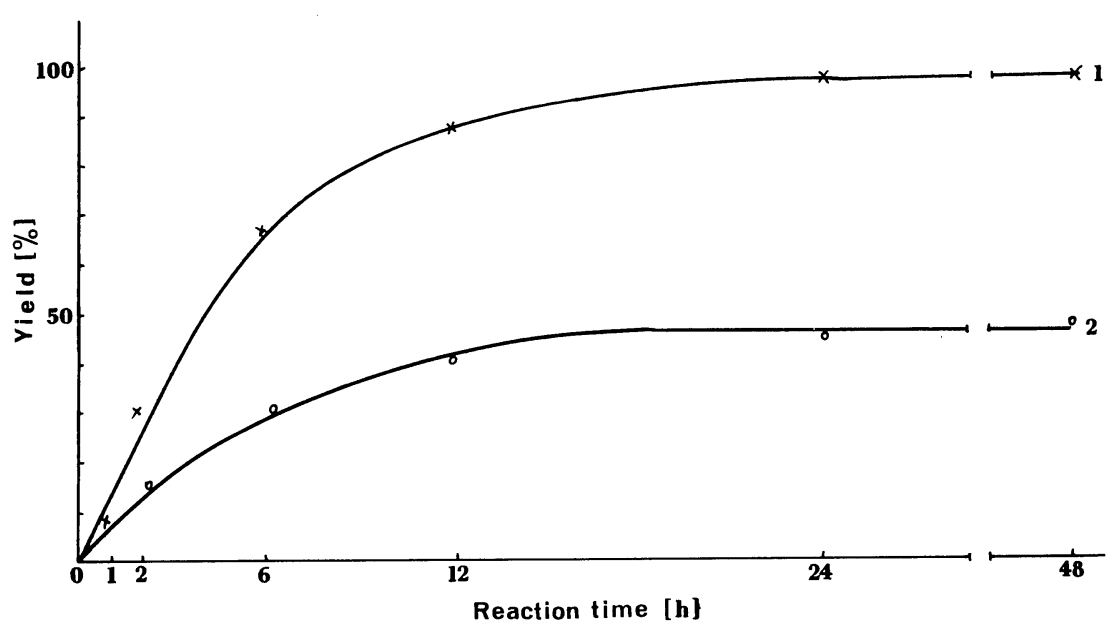

Figure 1. Dependence of the yield of dibenzyl carbonate in reaction of $\mathrm{K}_{2} \mathrm{CO}_{3}$ and $\mathrm{PhCH}_{2} \mathrm{Br}$ in the presence of 18 -crown- 6 ether $(x)$ and TEBA $(O)$ on reaction time. Reaction conditions are shown in Table II.

homogeneous systems, ${ }^{7}$ also appeared to be effective activators for the reaction described by eq 1 . However, the yield of dibenzyl carbonate obtained in the presence of the above polyamines, as well as the commonly used phase-transfer catalyst (TEBA), was lower than that obtained in the presence of the crown ethers and polyglymes, and fluctuated between $30-50 \%$ with respect to $\mathrm{K}_{2} \mathrm{CO}_{3}$.

The dependence on time of the yield of dibenzyl carbonate obtained from the reaction of $\mathrm{K}_{2} \mathrm{CO}_{3}$ and benzyl bromide using 18 -crown- 6 ether and TEBA as activating agents is presented in Figure 1. The yield appeared to increase linearly for $6 \mathrm{~h}$ and, after $24 \mathrm{~h}$, achieved a plateau reaching almost $100 \%$ in the case of the crown ethers and $45 \%$ in the case of TEBA.

Table III presents the dependence of the yield of dibenzyl carbonate on the amount of 18-crown-6 ether. It was found that for the molar ratio (crown ether $/ \mathrm{K}_{2} \mathrm{CO}_{3}$ ) ca. $1: 50$ the carbonate yield after $24 \mathrm{~h}$ of reaction is about $70 \%$, but for the $c a$. $1: 10$ molar ratio, nearly $100 \%$ under the same conditions. In the absence of cation complexing agent, only traces of dibenzyl carbonate were observed after $72 \mathrm{~h}$.

Replacement of $\mathrm{K}_{2} \mathrm{CO}_{3}$ in the reaction of eq 1 by other carbonates such as $\mathrm{Na}_{2} \mathrm{CO}_{3}$ caused a severalfold decrease in yield, and in the case of $\mathrm{BaCO}_{3}$ and $\mathrm{CaCO}_{3}$, only traces of dibenzyl carbonate were obtained (Table IV).
Table III. Effect of the amount of crown ether on the dibenzyl carbonate yield in the reaction of $\mathrm{K}_{2} \mathrm{CO}_{3}$ with $\mathrm{PhCH}_{2} \mathrm{Br}^{\mathrm{a}}$

\begin{tabular}{llcc}
\hline \multicolumn{2}{c}{ 18-Crown-6 } & & Yield \\
\cline { 1 - 1 } $\mathrm{g}$ & $\mathrm{mmol}$ & & $\%$ \\
\hline 0 & 0 & traces $^{\mathrm{b}}$ \\
0.025 & 0.1 & 70 \\
0.05 & 0.2 & 85 \\
0.1 & 0.38 & 98 \\
0.5 & 1.9 & 97 \\
1.0 & 3.8 & 82 \\
\hline
\end{tabular}

a $\mathrm{PhCH}_{2} \mathrm{Br}, 84.2 \mathrm{mmol} ; \mathrm{K}_{2} \mathrm{CO}_{3}, 0.6 \mathrm{~g}$ (4.34 mmol); temp, $80^{\circ} \mathrm{C}$; time, $24 \mathrm{~h}$.

b Reaction time, $72 \mathrm{~h}$.

The synthesis of carbonate monomers was also carried out using respective alkyl potassium carbonates in reactions with alkyl halides. It appeared, however, that the diethyl carbonate yield obtained in the reaction of ethyl potassium carbonate with ethyl bromide in the presence of 18-crown-6 ether was much lower than when using $\mathrm{K}_{2} \mathrm{CO}_{3}$ (Table IV). This was probably the result of the presence of some remaining complexed ethanol in the initial ethyl potassium carbonate (vide the preparation of ethyl potassium carbonate in EXPERIMENTAL). causing a decrease in the reactivity of the ethyl carbonate anion. 
Table IV. Relation between the yield of dialkyl carbonates and type of metal carbonate used ${ }^{\mathrm{a}}$

\begin{tabular}{|c|c|c|c|c|c|c|}
\hline \multicolumn{3}{|c|}{ Metal carbonate } & \multicolumn{3}{|c|}{ Alkyl bromide } & \multirow{2}{*}{$\begin{array}{c}\begin{array}{c}\text { Alkyl } \\
\text { carbonate } \\
\text { yield }\end{array} \\
\frac{\%}{\%}\end{array}$} \\
\hline & $\mathrm{g}$ & $\mathrm{mmol}$ & & g & $\mathrm{mmol}$ & \\
\hline $\mathrm{K}_{2} \mathrm{CO}_{3}$ & 0.6 & 4.34 & $\mathrm{PhCH}_{2} \mathrm{Br}$ & 14.4 & 84.2 & 98 \\
\hline $\mathrm{K}_{2} \mathrm{CO}_{3}$ & 0.6 & 4.34 & $\mathrm{EtBr}^{\mathrm{b}}$ & 14.5 & 133.0 & 35 \\
\hline $\mathrm{Na}_{2} \mathrm{CO}_{3}{ }^{\mathrm{c}}$ & 0.46 & 4.34 & $\mathrm{PhCH}_{2} \mathrm{Br}$ & 14.4 & 84.2 & 28 \\
\hline $\mathrm{CaCO}_{3}$ & 0.43 & 4.34 & $\mathrm{PhCH}_{2} \mathrm{Br}$ & 14.4 & 84.2 & traces \\
\hline $\mathrm{BaCO}_{3}$ & 0.86 & 4.34 & $\mathrm{PhCH}_{2} \mathrm{Br}$ & 15.5 & 90.6 & traces \\
\hline $\mathrm{C}_{2} \mathrm{H}_{5} \mathrm{OCOOK}$ & 0.56 & 4.34 & $\mathrm{EtBr}^{\mathrm{b}}$ & 7.3 & 67.0 & 12 \\
\hline
\end{tabular}

a 18 -Crown-6 ether, $0.1 \mathrm{~g}(0.38 \mathrm{mmol})$; temp, $80^{\circ} \mathrm{C}$; time $48 \mathrm{~h}$.

b Reaction temp, $42^{\circ} \mathrm{C}$.

c $15-$ Crown-5 ether $(0.1 \mathrm{~g})$ was used instead of 18-crown-6.

Table V. Effect of solvent on the dibenzyl carbonate yield in the reaction of $\mathrm{K}_{2} \mathrm{CO}_{3}$ and $\mathrm{PhCH}_{2} \mathrm{Br}^{\mathrm{a}}$

\begin{tabular}{|c|c|c|}
\hline \multirow{2}{*}{ Solvent } & \multirow{2}{*}{ Dielectric constant } & Yield \\
\hline & & $\%$ \\
\hline${ }^{\mathrm{b}}$ & 2.2 & 98 \\
\hline Dioxane & 2.2 & 82 \\
\hline THF & 7.6 & 42 \\
\hline Diglyme & 7.5 & 95 \\
\hline Acetonitrile & 37.5 & 98 \\
\hline Ethanol & 24.3 & 30 \\
\hline DMSO & 45.0 & 35 \\
\hline Benzene & 2.2 & 67 \\
\hline
\end{tabular}

a Benzyl bromide, $2.96 \mathrm{~g}$ (17.4 mmol); $\mathrm{K}_{2} \mathrm{CO}_{3}, 0.6 \mathrm{~g}(4.34$ $\mathrm{mmol})$; 18 -crown-6 ether, $0.1 \mathrm{~g}(0.38 \mathrm{mmol})$; solvent, $10 \mathrm{~cm}^{3}$; temp, $80^{\circ} \mathrm{C}$; time, $24 \mathrm{~h}$.

b Benzyl bromide, $14.4 \mathrm{~g}(84.2 \mathrm{mmol})$.

Table $\mathrm{V}$ shows the effect of the type of solvent used on the yield of dibenzyl carbonate in the reaction of benzyl bromide with $\mathrm{K}_{2} \mathrm{CO}_{3}$ in the presence of 18-crown-6. Acetonitrile and ethers such as diglyme and dioxane appeared to be the best solvents for the reaction in eq 1 . Ethanol had little effect. In this case the small reaction yield is related to the ability of ethanol to solvate both cations and anions which, despite the high dielectric constant of ethanol, considerably decrease the carbonate anion reactivity.

Under ordinary conditions, $\mathrm{K}_{2} \mathrm{CO}_{3}$ is insoluble even in polar solvents which readily solvate cations such as DMSO or DMF, and a reaction with benzyl bromide does not take place. The introduction to the reaction system of activating agents such as crown ethers causes abstraction of potassium cations from the crystalline lattice. This results in the formation (according to eq 1a) of a complex of increased liophility and ability of the "naked" carbonate anion to undergo nucleophilic substitution with an alkyl bromide.

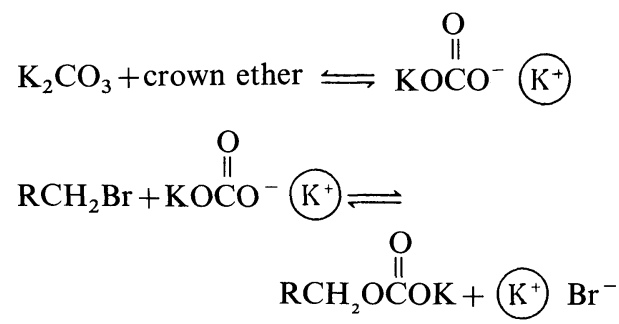

$\stackrel{\stackrel{\mathrm{O}}{\|}}{\mathrm{K}^{+}} \mathrm{Br}^{-}+\mathrm{RCH}_{2} \mathrm{OCOK} \rightleftharpoons$<smiles>O=C(OC[Ge](=O)Br)c1ccccc1</smiles>

$$
\begin{aligned}
& \stackrel{\stackrel{\mathrm{O}}{\|} \mathrm{RCH}_{2} \mathrm{OCO}^{-}}{\mathrm{K}^{+}}+\mathrm{RCH}_{2} \mathrm{Br}
\end{aligned}
$$

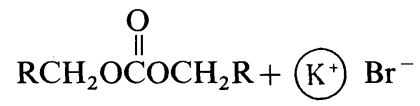

The reaction of alkyl bromides with activated potassium carbonates is reversible (eq $1 \mathrm{~b}$ ) and the 
Table VI. Polycarbonates obtained from transesterification of diethyl carbonate with diol or diphenol

\begin{tabular}{|c|c|c|c|}
\hline $\begin{array}{c}\text { Diol } \\
\text { or Diphenol }\end{array}$ & Catalyst & Reaction conditions & $\begin{array}{l}\text { Polycarbonate } \\
\qquad \frac{\eta_{\text {red. }}}{\mathrm{dlg}^{-1}}\end{array}$ \\
\hline $\mathrm{HO}-\left(\mathrm{CH}_{2}\right)_{4} \mathrm{OH}$ & $\begin{array}{l}\mathrm{Al}\left(\mathrm{Oi}-\mathrm{C}_{3} \mathrm{H}_{7}\right)_{3} \\
\mathrm{Ti}(\mathrm{OBu})_{4}\end{array}$ & $\begin{array}{l}120^{\circ} \mathrm{C}, 5 \mathrm{~h} \rightarrow 120^{\circ} \mathrm{C} / 20 \mathrm{mmHg}, 2 \mathrm{~h} \\
120^{\circ} \mathrm{C}, 4 \mathrm{~h} \rightarrow 120^{\circ} \mathrm{C} / 20 \mathrm{mmHg}, 3 \mathrm{~h}\end{array}$ & $\begin{array}{l}0.5^{\mathrm{a}} \\
0.4\end{array}$ \\
\hline $\mathrm{HOCH}_{2}-\bigcirc-\mathrm{CH}_{2} \mathrm{OH}$ & $\mathrm{Ti}(\mathrm{OBu})_{4}$ & $125^{\circ} \mathrm{C}, 4 \mathrm{~h} \rightarrow 120^{\circ} \mathrm{C} / 20 \mathrm{mmHg}, 2 \mathrm{~h}$ & \\
\hline $\mathrm{HO}-\widehat{C}$ & $\begin{array}{l}\mathrm{Al}(\mathrm{OPh})_{3} \\
\mathrm{Ti}(\mathrm{OBu})_{4}\end{array}$ & $\begin{aligned} \rightarrow & 200^{\circ} \mathrm{C} / 2 \mathrm{mmHg}, 1 \mathrm{~h} \\
& 125^{\circ} \mathrm{C}, 4 \mathrm{~h} \rightarrow 120^{\circ} \mathrm{C} / 20 \mathrm{mmHg}, 2 \mathrm{~h} \\
\rightarrow & 200^{\circ} \mathrm{C} / 2 \mathrm{mmHg}, 1 \mathrm{~h}\end{aligned}$ & $\begin{array}{l}\overline{-b}^{\mathrm{b}} \\
0.1 \\
0.1\end{array}$ \\
\hline
\end{tabular}

a $M_{n}=16500$ measured at $30^{\circ} \mathrm{C}$ in chloroform by a vapor-pressure osmometer.

b Insoluble in $\mathrm{CHCl}_{3}$.

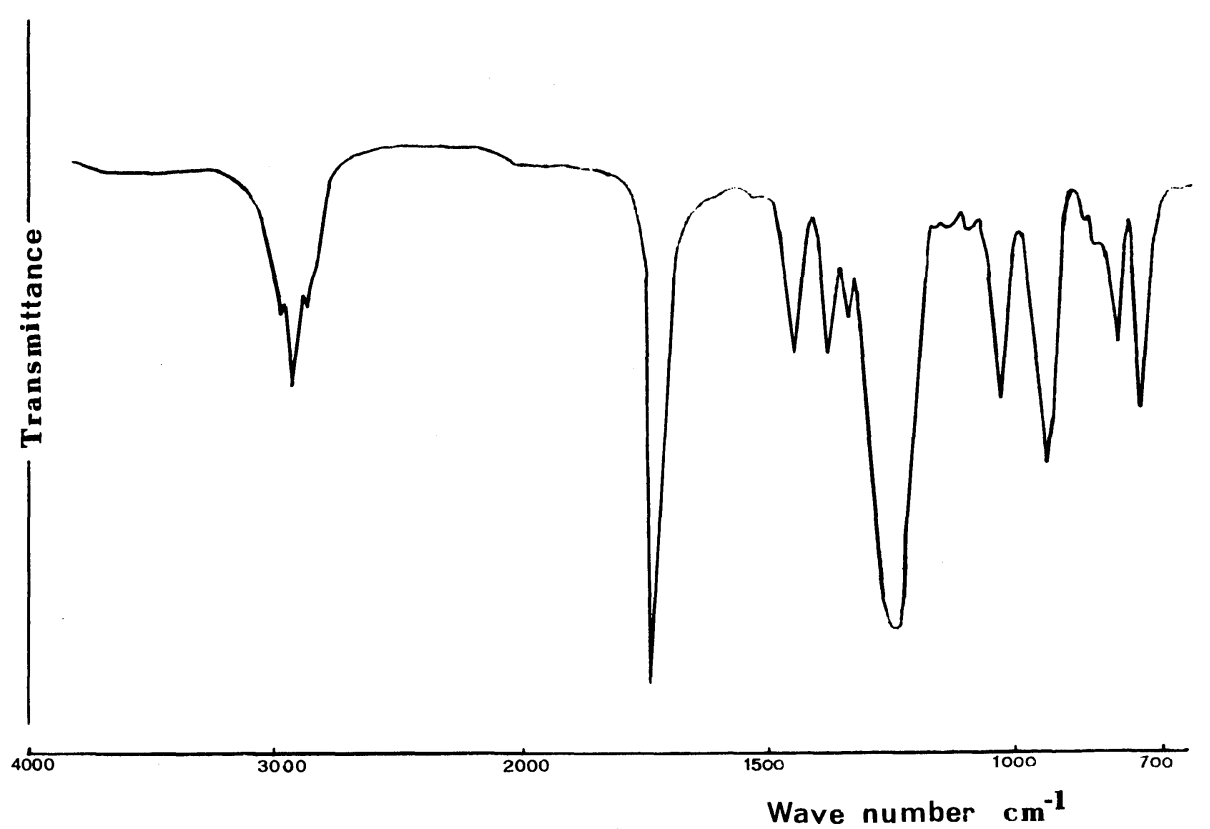

Figure 2. IR spectrum of poly( $p$-xylylene carbonate) obtained from the transesterification of diethyl carbonate and $p$-xylylene glycol. Conditions of transesterification are shown in Table VI.

yield of alkylpotassium carbonates depends on the excess of the bromo-derivatives used and the difference in nucleophilicity of the carbonates and bromide anions. An important role is also played by the equilibrium of the reaction in eq $1 \mathrm{c}$. This depends on the difference in solubility of the respective potassium salts and bromide and alkylcarbonate.
The greater reactivity of the alkyl bromides than of the corresponding chlorides in reactions - with $\mathrm{K}_{2} \mathrm{CO}_{3}$ results from the smaller basicity and nucleophilicity of the bromide anion than that of chloride one. Thus the reactions eq $1 \mathrm{~b}$ and eq $1 \mathrm{~d}$, which are nucleophilic substitution reactions, proceed easier in the case of alkyl bromides since they 
abstract bromide anions more easily than alkyl chloride abstracts chloride anions.

From studies carried out on the reaction in eq 1, it appears that alkyl-, allyl, or benzyl carbonates, with good yeilds reaching in the latter case to $100 \%$ with respect to the $\mathrm{K}_{2} \mathrm{CO}_{3}$ used, could be obtained when using metal cation complexing agents such as crown ethers or much cheaper polyglymes, polyamines or ammonium salts.

The carbonate monomers were transesterified with diols and diphenols using the catalysts shown in Table VI, along with the results of polycarbonate synthesis. The IR spectrum of the polycarbonate obtained from diethyl carbonate and $p$-xylylene glycol, presented in Figure 2, contains absorption bands at 1740 and $1260 \mathrm{~cm}^{-1}$ characteristic for the stretching vibrations of carbonyl groups and $\mathrm{C}-\mathrm{O}$ bonds. This spectrum does not contain absorption bands in the $3500 \mathrm{~cm}^{-1}$ region, indicating the lack of hydroxyl groups in the polymer. It is similar to that of the polycarbonate obtained from the condensation of $\mathrm{K}_{2} \mathrm{CO}_{3}$ and 4-bromomethylbenzyl bromide. In this latter spectrum also an absorption band at $760 \mathrm{~cm}^{-1}$, characteristic for $\mathrm{C}-\mathrm{Br}$ stretching vibrations occurs. ${ }^{3}$
Acknowledgement. This work was financed by the Polish Academy of Sciencies (Problem MRI-31).

\section{REFERENCES}

1. K. Soga, Y. Toshida, S. Hosoda, and S. Ikeda, Makromol. Chem., 178, 2747 (1977); ibid., 179, 2379 (1978).

2. G. Rokicki, W. Kuran, and J. Kiełkiewicz, J. Polym. Sci., Polym. Chem. Ed., 20, 967 (1982).

3. K. Soga, S. Hosoda, and S. Ikeda, J. Polym. Sci., Polym. Lett. Ed., 15, 611 (1977); K. Soga, S. Hosoda, and S. Ikeda, J. Polym. Sci., Polym. Chem. Ed., 17, 517 (1979).

4. S. Sakai, T. Fujinami, T. Yamada, and S. Furusawa, Nippon Kagaku Kaishi, 10, 1789 (1975).

5. N. Yamazaki, S. Nakahama, and F. Higashi, Ind. Eng. Chem. Prod. Res. Dev., 18, 249 (1979).

6. G. Gokel and D. Cram, J. Org. Chem., 39, 1070 (1974).

7. H. E. Simmons and C. H. Park, J. Am. Chem. Soc., 90, 2428 (1968).

8. S. T. Bowden, J. Chem. Soc., 310 (1939).

9. S. T. Bowden and E. T. Butler, J. Chem. Soc., 78 (1939).

10. U.S. Patent 2410305 (1940); Chem. Abstr., 41, 624 (1947). 